\title{
Research on Crushing Concrete Members by High-Voltage Pulse Discharge Technology
}

\author{
Xiaodong Wang $\mathbb{D}^{D}$, Jiaxu Du $\mathbb{D}$, and Ningjing Li $\mathbb{C}$ \\ School of Architectural and Civil Engineering, Harbin University of Science and Technology, Harbin 150080, China \\ Correspondence should be addressed to Xiaodong Wang; wangxiaodong-hit@126.com
}

Received 22 February 2021; Revised 30 April 2021; Accepted 7 May 2021; Published 24 May 2021

Academic Editor: Piotr Smarzewski

Copyright (c) 2021 Xiaodong Wang et al. This is an open access article distributed under the Creative Commons Attribution License, which permits unrestricted use, distribution, and reproduction in any medium, provided the original work is properly cited.

\begin{abstract}
High-voltage pulse discharge (HVPD) is an energy-saving, efficient, and green technique, which has broad prospects in concrete crushing. The finite element models of the concrete beam, slab, and column segments were established with ANSYS/LS-DYNA finite element software. Based on the principle of equal impact pressure, the shock wave generated by the fuse explosion caused by HVPD of $50 \mathrm{~kJ}$ is equivalent to the impact load of explosive blasting, and the stress of concrete beam segment was analyzed. The finite element models of the concrete beam sections were established to investigate the influence of diameter and spacing of the holes on the crushing effect of concrete beam segments. The width $\times$ height of each beam segment is $400 \mathrm{~mm} \times 800 \mathrm{~mm}$, and there are six types of beam segment length: $600 \mathrm{~mm}, 700 \mathrm{~mm}, 800 \mathrm{~mm}, 900 \mathrm{~mm}, 1000 \mathrm{~mm}$, and $1100 \mathrm{~mm}$. Two holes are drilled vertically on the surface of the width $\times$ length of each beam segment. The spacing of holes corresponding to beam segments of each length type is $200 \mathrm{~mm}, 300 \mathrm{~mm}, 400 \mathrm{~mm}, 500 \mathrm{~mm}, 600 \mathrm{~mm}$, and $700 \mathrm{~mm}$, respectively. The hole depth of each beam segment is $650 \mathrm{~mm}$, and there are three types of aperture: $30 \mathrm{~mm}, 50 \mathrm{~mm}$, and $70 \mathrm{~mm}$. The analysis results show that the crushing effect of concrete beam segments increases with the increase of aperture and the decrease of hole spacing. According to the crushing effect of the beam segments, the aperture of $50 \mathrm{~mm}$, the spacing of $400 \mathrm{~mm}$, and the hole end (edge) spacing of $250 \mathrm{~mm}$ were determined as the optimal hole layout scheme. The finite element models of concrete slabs and columns were established. The square concrete slab thickness is $140 \mathrm{~mm}$ and side length is $700 \mathrm{~mm}, 800 \mathrm{~mm}$, and $900 \mathrm{~mm}$, respectively. Double-row holes were arranged in the slabs and the aperture is $50 \mathrm{~mm}$ and the hole spacing is $200 \mathrm{~mm}, 300 \mathrm{~mm}$, and $400 \mathrm{~mm}$, respectively. The section sizes of concrete columns are $500 \mathrm{~mm} \times 500 \mathrm{~mm}, 600 \mathrm{~mm} \times 600 \mathrm{~mm}$, and $700 \mathrm{~mm} \times 700 \mathrm{~mm}$, respectively, and the aperture is $50 \mathrm{~mm}$ and the hole distance is $400 \mathrm{~mm}$. According to the results of analysis, the optimal hole distribution scheme of concrete slab and column is chosen as the aperture of $50 \mathrm{~mm}$ and hole distance of $400 \mathrm{~mm}$. The principle of the layout of multirow holes is that the spacing of row is not more than $400 \mathrm{~mm}$, and the margin is not more than $250 \mathrm{~mm}$.
\end{abstract}

\section{Introduction}

HPVD refers to the accumulation of low power energy for a period of time and then release high power energy for a short time [1]. In the mid-20th century, the Soviet Union has used the principle of hydroelectric effect to dismantle concrete foundation, but it was not popularized [2]. Then, the Ukrainian Academy of Sciences developed the electrohydraulic crushing device, which dismantled the whole concrete block with an efficiency of $3 \mathrm{~m}^{3} / \mathrm{h}$. The Moscow Power Professional Installation Company adopted a new type of chemical mixture electrolyte in the application of the device.
The electrolyte can release extra energy after chemical reaction after HPVD, thus increasing the impact pressure action time on the concrete structure and improving the concrete demolition capacity to $6 \sim 8 \mathrm{~m}^{3} / \mathrm{h}$ [3]. Bluhm et al. from the Karlsruhe Research Center in Germany developed a semi-industrial prototype for concrete crushing and recycling. The equipment can be used to recycle large volumes of concrete after crushing, and the working efficiency can reach $1000 \mathrm{~kg} / \mathrm{h}$ [4]. After 2000, the Russian Academy of Sciences has developed a HPVD device which can be used for the crushing of electrohydraulic effect. The device can form a strong shock wave in the concrete predrilling and 
make it broken, which has important value for engineering application [5]. Hitachi Shipbuilding Co., Ltd., in Japan has manufactured ESG-7K2 discharge shock generating device [6], which has been applied to the demolition of concrete and masonry buildings, the maintenance of road and bridge structures, rock breaking, underwater cleanup and other practical projects, and achieved good results. The energy consumption of the equipment is $0.1-0.2 \mathrm{~kW} \cdot \mathrm{h} / \mathrm{m}^{3}$. NASA has also mined the moon's rocks using a HPVD crushing technique. With the continuous improvement of the research level of pulse power, the HPVD crushing technology is gradually extended to the fields of mining engineering, environmental engineering, geotechnical engineering, construction engineering, and so on, showing a good application prospect.

As urbanization picks up, the demolition demand is continuously on the rise, for the reasons as follows:

(1) The requirements for living environment have been increased. Taking China as an example, there are over 60 billion $\mathrm{m}^{2}$ of existing buildings [7], and the previous small rooms, column nets, and apartments can no longer satisfy the high requirements of production and living.

(2) The reliability level of building structure design was low in the past, and the reliability level of structure decreased with the change of material quality over time. So, the building would not be safe. According to the preliminary investigation, $30 \%-50 \%$ of the buildings in China already have some problems such as functional degradation or safety failure [8], which need to be demolished.

(3) Some buildings must be demolished because of the development of urban planning and road network planning.

The HPVD technology has the advantages of high efficiency, low pollution, noise control, and no harmful gas [9-11]. It can make up for the traditional mechanical, blasting concrete crushing technology such as high cost, long period, and the shortcomings of low efficiency [12], especially suitable for the environment, security restrictions to demand higher population intensive areas.

Although there are some experimental studies on HVPD technology, the experimental data are inadequate and mostly for the purpose of rock crushing [13-15]. There is a big difference between rock and concrete in mechanical properties and material composition, so the research results obtained from rock crushing cannot be directly applied to concrete, and from the material composition of rock which can be considered to be composed of a single material; concrete material composition is more complex [16]. So, the finite element analysis models of concrete beam, slab, and column sections were established by ANSYS/LS-DYNA software. The impact load formed by HPVD is applied to the concrete members to analyze the whole process. The influence of different parameters on the crushing effect was inspected, such as hole diameter, spacing, row spacing, and end (edge) spacing. Then, the concrete structure crushing optimal scheme by HVPD technology was proposed.

\section{Principle of HVPD Crushing}

There are three types of HVPD crushing technology as follows:

2.1. Fuse Explosion Method. By fuse explosion breaking method, the drill bit is inserted into the crack of the broken object, and the metal fuse is wound between two electrodes of the drill bit. The wire rises sharply in temperature by the high-voltage impact current, and a plasma forms from the fuse and expands rapidly. Then, the surrounding objects are subjected to strong impact loads, which will be broken [17].

2.2. Electrohydraulic Effect Method. This method was put forward by the Soviet scholar Yutkin and applied in stamping, crushing, and sand cleaning of castings. The main process of the work is to drill holes in the object and place the discharge electrode into the holes filled with electrolyte (usually copper sulfate). When the high-voltage impulse current is introduced, the electrons and molecules in the electrolyte collide and cause electron avalanche, which is converted into plasma. The plasma expands instantaneously and exerts an impact pressure on the surrounding objects, and then breaking is caused [18].

2.3. Direct Discharging Method. By this method, the object is immersed in the electrolyte, and the two electrodes are placed on the surface at a certain spacing. When the impulse voltage is applied, the interior of the object between the electrodes is broken down to form a plasma channel. Then, the object will be broke down with the expansion of plasma [19].

Compared with the three crushing methods mentioned above, the direct discharge method requires the highest output voltage, so the volume, dead weight, and cost of the equipment are also the highest. That is often used in mass engineering such as rock excavation. The electrohydraulic effect method has higher requirement on the quality of electrolyte. So, the electrolyte cannot be broken down during the operation. That not only affects the construction efficiency but also may lead to the high-voltage current breakdown equipment, leading to safety accidents. The fuse explosion technology has the advantages of good discharge reliability, low voltage, small volume, and cost and is more suitable for construction engineering. In this paper, the theory of concrete crushing is studied based on the technology of fuse explosion.

\section{The Model of HVPD Concrete Crushing}

Based on the characteristic of the impact load caused by HVPD, the whole process of the concrete beams, slabs and, columns was simulated and analyzed by the ANSYS/LSDYNA software.

3.1. Material Model. It is assumed that the concrete material is average and isotropy, and the sealing material covered on the borehole to prevent punching has the same physical 
characteristics as concrete to facilitate the observation of the development of cracks. MAT_72R3 (Concrete_Damage_Rel3) is adopted to simulate concrete, which can reflect the dynamic response of concrete members under impact load [20], and the unit length is $10 \mathrm{~mm}$. The yield surface and constitutive relation of the MAT_72R3 model is shown in Figure 1. It can be seen from Figure 1 that the model consists of three parts: initial yield surface, failure surface, and residual strength surface [21].

The model can simulate the change of the subsequent yield surface between the initial yield surface and the ultimate yield surface and also simulate the change of the softening surface between the ultimate strength surface and the residual strength surface [22]. Similar to the Concrete_Damage model, the damage parameter is introduced into the subsequent formulas of yield surface and softening surface, and the difference between tension and compression, strain rate effect, and volume damage effect in triaxial tension is considered [23]. The damage and strain rate effect of concrete under impact load can be effectively considered. EOS8 model is introduced to consider the effect of strain rate on the yield strength and damage of concrete. The model reflects the function relationship between the hydrostatic pressure and the volume strain of concrete under tension and compression [24].

The development of cracks is described by adding the failure criterion of $*$ MAT_ADD_EROSION. Defining the maximum failure tensile stress may delete the element prematurely, so the compressive and shear effects of these elements that reach the maximum principal stress cannot be considered. The element may be removed prematurely by defining the maximum failure tensile stress. The cracking caused by tension of concrete may be exaggerated, as it is impossible to consider the compressive and shear effects of the deleted elements that reach the maximum principal stress. By defining the maximum principal strain as failure strain and controlling the deletion of concrete element, the cracking of concrete can be effectively simulated.

3.2. Application of Impact Load. The impact pressure caused by electrohydraulic effect is affected by many factors, such as peak pressure, circuit capacitance, and discharge voltage. The release energy of discharge equipment directly affects the impact pressure. Based on the experimental results of shock wave characteristics of discharge in liquid conducted by Touya [25], the empirical formula of shock pressure $P$ in the annular direction of the hole is shown in the following equation:

$$
P=\frac{9000}{d} E_{1}^{0.35} .
$$

In this formula, $E_{1}$ equals to energy released in liquid and $d$ equals to distance between discharging point and test point.

Based on the principle of equal impact pressure, the impact load of HVPD is equivalent to the shock wave generated by TNT explosive explosion, which acts on the side wall of the borehole in a circular direction. The model of
*MAT_HIGH_EXPLOSIVE_BURN material built in LSDYNA program is used for simulation, and the shock wave generated can be propagated as a cylinder from the borehole. The state equation of the model is shown in the following equation:

$$
\begin{aligned}
P= & A\left(1-\frac{\omega}{R_{1} V}\right) \exp \left(-R_{1} V\right) \\
& +B\left(1-\frac{\omega}{R_{2} V}\right) \exp \left(-R_{2} V\right)+\frac{\omega E_{0}}{V} .
\end{aligned}
$$

In this formula, $A, B, R_{1}, R_{2}$, and $\omega$ are the constants determined by the test, for example, TNT explosive with density of $1.2 \mathrm{~g} / \mathrm{cm}^{3}$ can be taken as $A=741 \mathrm{GPa}$, $B=689 \mathrm{GPa}, \omega=0.35, R_{1}=5.56$, and $R_{2}=1.65[26] ; \mathrm{V}$ is the relative volume, which is the ratio of the expansion volume of explosive products to the initial volume; and $E_{0}$ is the initial internal energy density.

\section{Test of Crushing Concrete Members by HVPD}

4.1. Test Equipment. A HPVD equipment was designed and manufactured to verify the effect of HVPD crushing concrete structure, as shown in Figure 2. The equipment is composed of ball gap discharge switch, transformer, capacitor, console, distribution box, and so on. The maximum charging voltage is $100 \mathrm{kV}$, and the peak energy of a single release is $100 \mathrm{~kJ}$. The discharge electrode is shown in Figure 3.

4.2. The Parameters of Specimens. The compressive strength of the concrete is $40 \mathrm{MPa}$, the tensile strength is $3.8 \mathrm{MPa}$, the density is $2300 \mathrm{~kg} / \mathrm{m}^{3}$, the elastic modulus is $33.0 \mathrm{GPa}$, and the Poisson's ratio is 0.25 .

4.2.1. A Concrete Block. The section size of the concrete cube test block is $300 \mathrm{~mm} \times 300 \mathrm{~mm} \times 300 \mathrm{~mm}$, drilling a hole vertically down the center of the upper surface of the concrete block with diameter of $40 \mathrm{~mm}$ and depth of $270 \mathrm{~mm}$.

4.2.2. A Reinforced Concrete Slab. The side length of square concrete slab is $1600 \mathrm{~mm}$ and the thickness is $140 \mathrm{~mm}$. The longitudinal steel bars with a diameter of $8 \mathrm{~mm}$ and a spacing of $200 \mathrm{~mm}$ are arranged in both directions in the slab. The tensile yield strength of reinforcement is $380 \mathrm{MPa}$. The hole row distance is $400 \mathrm{~mm}$, the hole diameter is $40 \mathrm{~mm}$, and the hole depth is $120 \mathrm{~mm}$. The distance from the outermost hole to the edge of the slab is $200 \mathrm{~mm}$.

4.2.3. A Reinforced Concrete Column. The section size of the concrete test column is $b \times h=600 \mathrm{~mm} \times 600 \mathrm{~mm}$, and the length is $2.4 \mathrm{~m} .8$ longitudinal steel bars with a diameter of $14 \mathrm{~mm}$ are uniformly arranged in the column. Two rows of holes are drilled vertically down along the upper surface of one side of the column. The spacing of the two rows is 


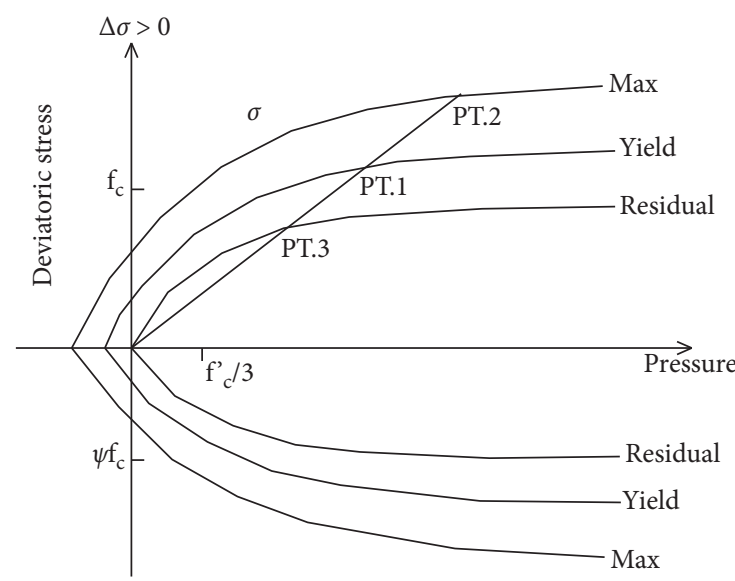

(a)

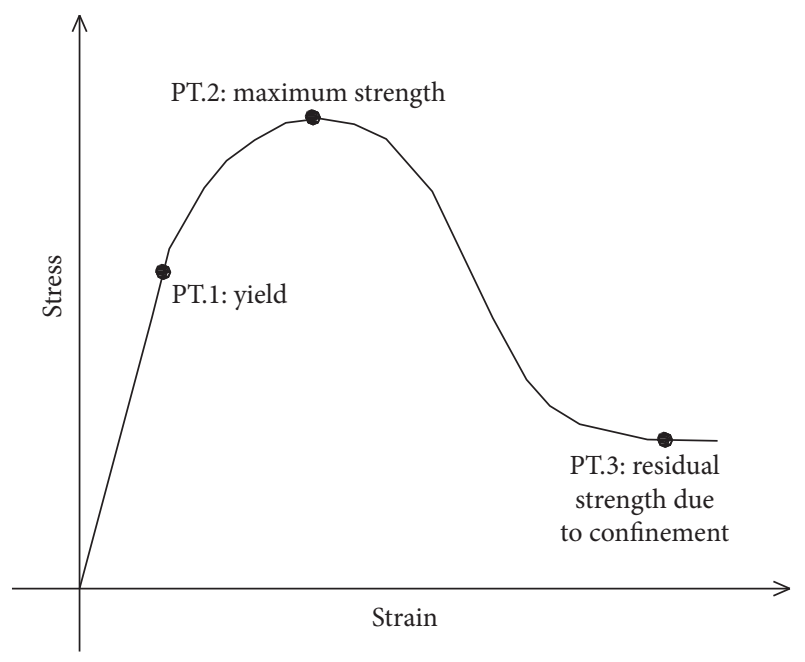

(b)

FIGURE 1: MAT_72R3 material model. (a) Yield surface of concrete model. (b) Constitutive relation of concrete model.

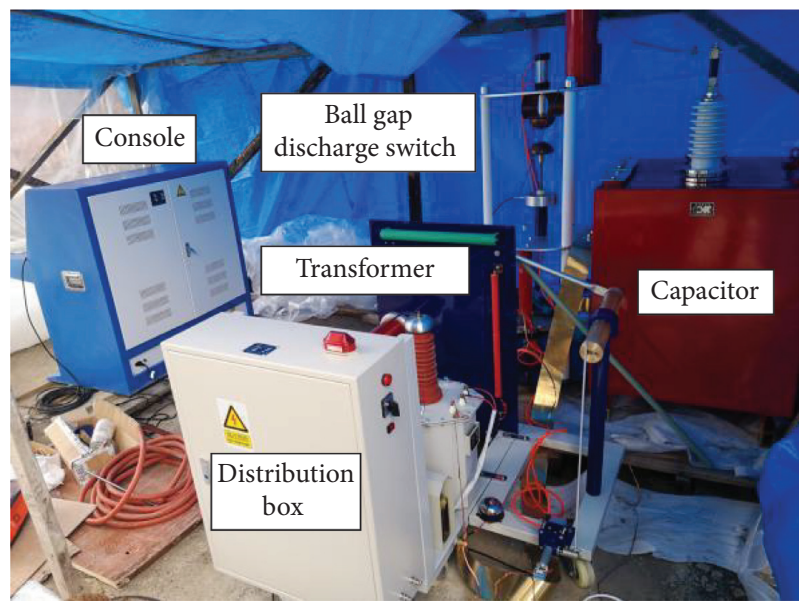

FIGURE 2: The high-voltage pulse generator.

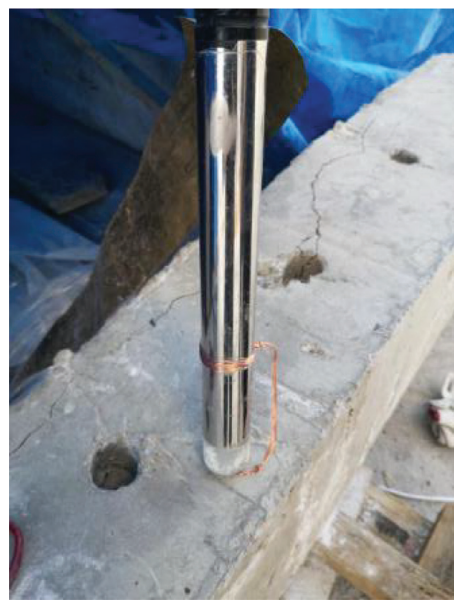

FIgure 3: The discharge electrode.
$200 \mathrm{~mm}$, the spacing of each row of holes is $300 \mathrm{~mm}$, the diameter of the holes is $400 \mathrm{~mm}$, the depth of the holes is $570 \mathrm{~mm}$, and the distance from the outermost hole to the edge of the column is $200 \mathrm{~mm}$.

4.3. Test Plan. The steps of the HVPC crushing test are first to drill holes in concrete members and then fill the hole with water and insert the electrode. Then, the high-voltage and low-voltage ends of the electrode are connected with aluminum wires. The hole with a covering is sealed, and then the power supply is connected to form a high-voltage pulse to break the concrete member. The working principle of impulse pressure caused by HVPD is shown in Figure 4.

4.4. Analysis of Test Results. The cracking effect of the test concrete block, slab, and column by HVPD method, which was analyzed by the ANSYS/LS-DYNA finite element software, is compared with the test results, as shown in Figures 5-7. It can be seen from Figures 5-7 that the development of concrete cracks formed by simulation analysis agrees well with the experimental results. It shows that the finite element model established in this paper has a certain precision for fracture development.

\section{Simulation of HVPD Crushing Concrete Members}

5.1. The Parameters. According to the symmetry of the concrete members, a segment of the concrete member is taken to simulate for simplifying the calculation. A liquid analog, the electrolyte, is provided in the hole and in which the explosive is placed. The effective discharge energy of HVPD is taken as $50 \mathrm{~kJ}$. The top of the hole was blocked to avoid liquid ejecting. 


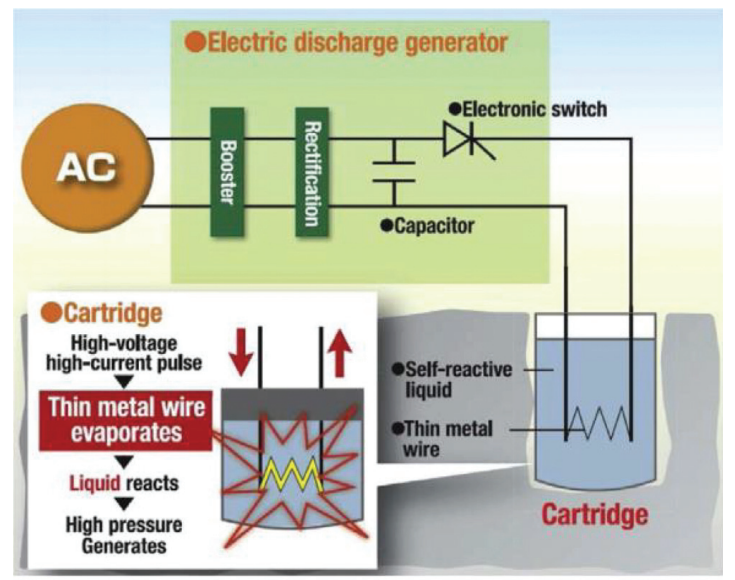

FIgURE 4: The shock pressure caused by HVPD.

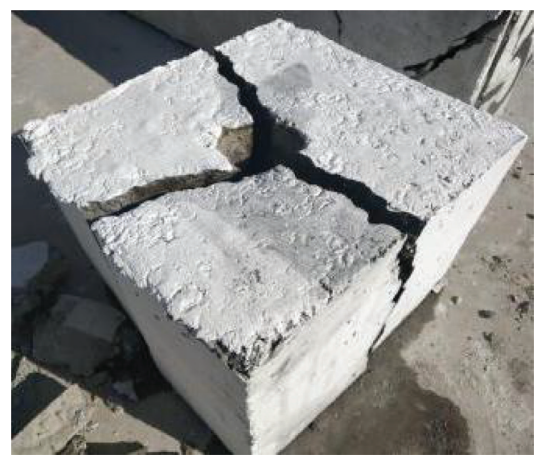

(a)

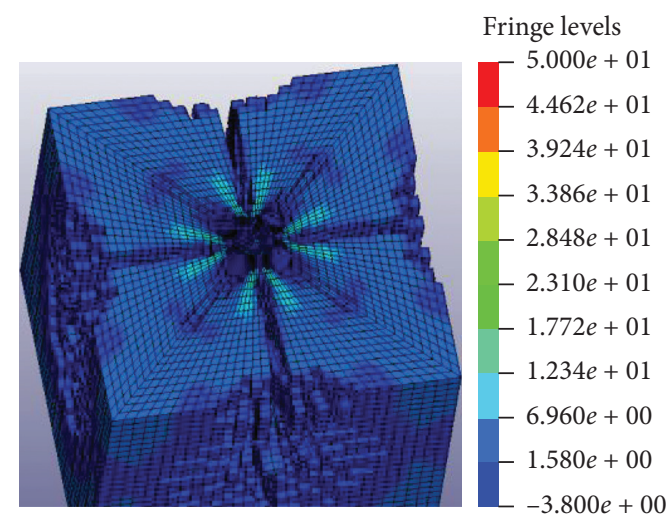

(b)

Figure 5: Comparison of experimental results and simulation results for a concrete block. (a) The test result. (b) The simulation result.

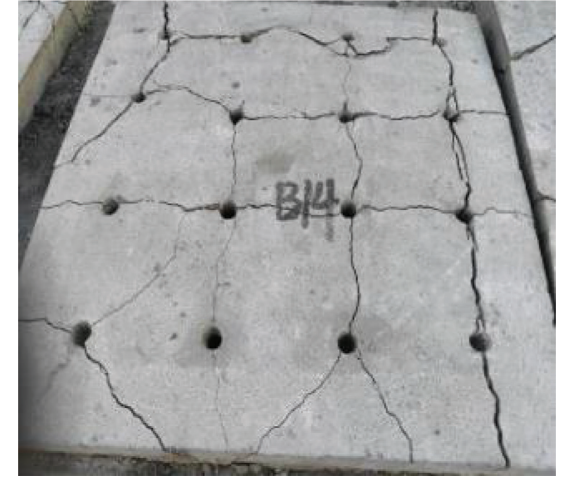

(a)

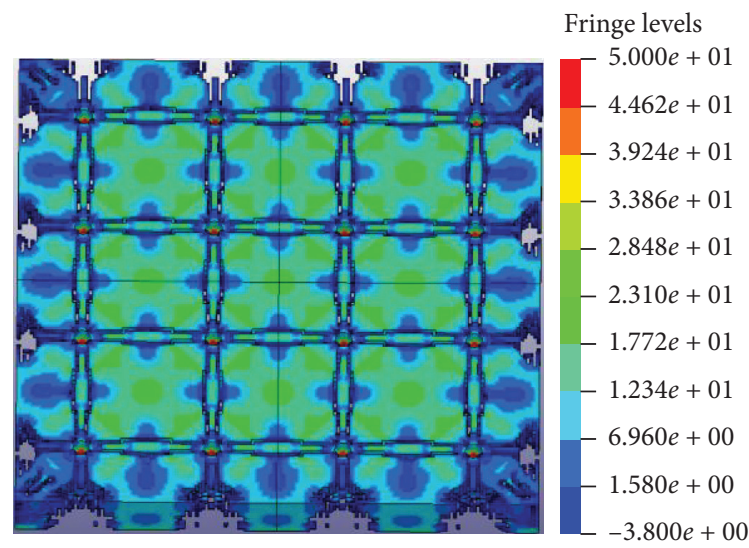

(b)

Figure 6: Comparison of experimental results and simulation results for a concrete slab. (a) The test result. (b) The simulation result.

\subsection{Analysis of Calculation Results}

5.2.1. Analysis of the Whole Process of a Concrete Beam with Single-Row Holes. Take a beam segment with a single row of holes as an example. The section size is width $\times$ height $=500 \mathrm{~mm} \times 800 \mathrm{~mm}$, the length is $900 \mathrm{~mm}$, the aperture is $50 \mathrm{~mm}$, the hole spacing is $400 \mathrm{~mm}$, and the end (edge) spacing is $250 \mathrm{~mm}$. The whole process analysis 


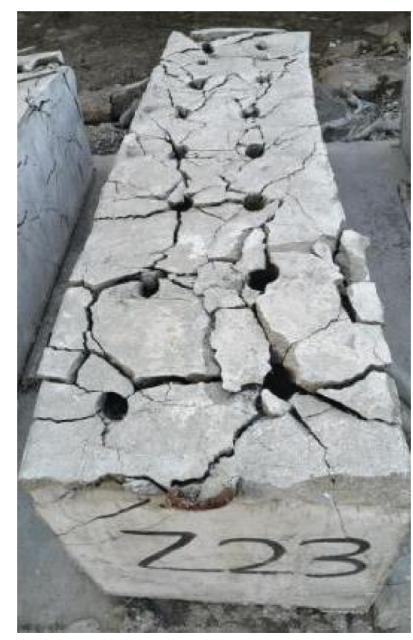

(a)

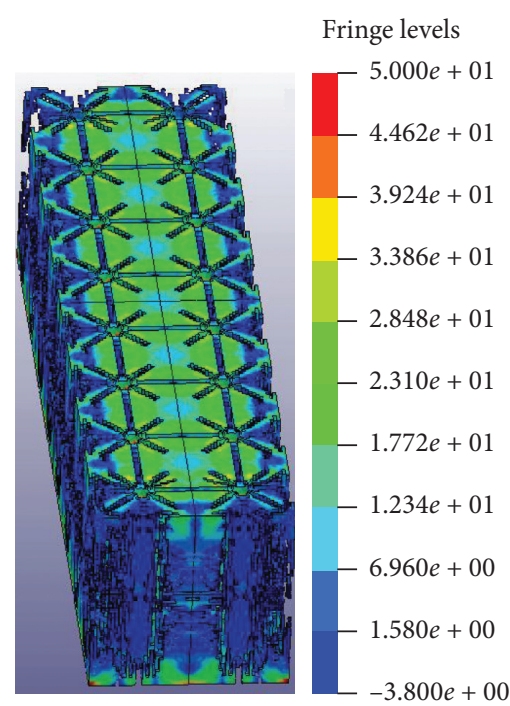

(b)

Figure 7: Comparison of experimental results and simulation results for a concrete column. (a) The test result. (b) The simulation result.

results of the beam segment under impact load are shown in Figure 8 .

It can be seen from Figure 8(a) that at the initial stage of concrete beam bearing impact load $(0-55 \mu \mathrm{s})$, the toroidal compressive stress waves with a small range appeared around the hole. At this time, no cracks formed around the hole. As the stress waves spread out of the hole, tiny cracks began to appear around it. But the stress waves did not intersect between the adjacent holes $(t=75 \mu \mathrm{s})$, as shown in Figure $8(\mathrm{~b})$. The stress waves expanded, and the stress waves intersect between the adjacent two holes. At the intersection of the stress waves, a tensile stress perpendicular to the line between the two holes was formed, and the crack centered on the hole extended around $(t=85 \mu \mathrm{s})$, as shown in Figure 8(c). When $t=95 \mu \mathrm{s}$, as shown in Figure $8(\mathrm{~d})$, the tensile stress formed at the intersection of stress waves reaches the tensile strength of the concrete beam segment, and the concrete beam segment is about to crack. But the cracks between the two holes were not connected. Then, longitudinal cracks appeared between the two holes, and the cracks centered on the holes basically extended to the outer edge of the concrete beam section $(t=120 \mu \mathrm{s})$, as shown in Figure $8(\mathrm{e})$. Then, the cracks of the two adjacent holes extended and formed a connection, and the lateral cracks with the holes as the center extend outward to the outer edge of the beam. The whole beam segment is divided into several pieces, so as to achieve the crushing effect.

5.2.2. Analysis of the Whole Process of a Concrete Beam with Multirow Holes. If the section size of the concrete member is large, multiple rows of holes should be arranged to achieve the crushing effect. Take a beam segment with two rows of holes as an example. The section size is width $\times$ height $=900 \mathrm{~mm} \times 1200 \mathrm{~mm}$, the length is $900 \mathrm{~mm}$, the aperture is $50 \mathrm{~mm}$, the hole spacing is $400 \mathrm{~mm}$, and the end (edge) spacing is $250 \mathrm{~mm}$. The whole process analysis results of the beam segment under impact load are shown in Figure 9.

As can be seen from Figure 9(a), at the initial stage $(0-60 \mu \mathrm{s})$ when the concrete beam bores the impact load, the toroidal compressive stress wave was generated around the hole. At this time, no cracks formed around the hole. As shown in Figure 9(b) $(t=95 \mu \mathrm{s})$, as the stress wave extended out of the hole, the stress waves between adjacent holes began to intersect. As shown in Figure 9(c) $(t=115 \mu \mathrm{s})$, tensile stress was formed at the junction perpendicular to the pressure wave interface between two adjacent holes, accompanied by microcracks. The fracture expanded, and this is the critical time for fracture connectivity between holes, as shown in Figure $9(\mathrm{~d})(t=125 \mu \mathrm{s})$. As shown in Figure $9(\mathrm{e})(t=140 \mu \mathrm{s})$, the crack extended outward from the center of the hole to the outer edge of the concrete beam segment, and the cracks between the holes are connected. Then, the concrete beam segment is broken into 9 main parts under the action of load, so as to achieve the crushing effect.

\subsubsection{Analysis of Simulation Results of Concrete Beams.} The section size of the concrete beams is width $\times$ height $=400 \mathrm{~mm} \times 800 \mathrm{~mm}$, and the length of the beam segments is $600 \mathrm{~mm}, 700 \mathrm{~mm}, 800 \mathrm{~mm}, 900 \mathrm{~mm}$, $1000 \mathrm{~mm}$, and $1100 \mathrm{~mm}$, respectively. Two holes were drilled vertically on the width $\times$ length surface of the beam segment, and the depth of the holes is $650 \mathrm{~mm}$ ad the aperture is $30 \mathrm{~mm}, 50 \mathrm{~mm}$, and $70 \mathrm{~mm}$, respectively. The hole spacing along the beam length direction is $200 \mathrm{~mm}, 300 \mathrm{~mm}$, $400 \mathrm{~mm}, 500 \mathrm{~mm}, 600 \mathrm{~mm}$, and $700 \mathrm{~mm}$, respectively. The hole spacing is the distance between the two hole centers, the hole edge spacing is the distance from the hole center to the side of the member, and the hole end spacing is the distance between the hole center and the left or right ends of the specimen. 


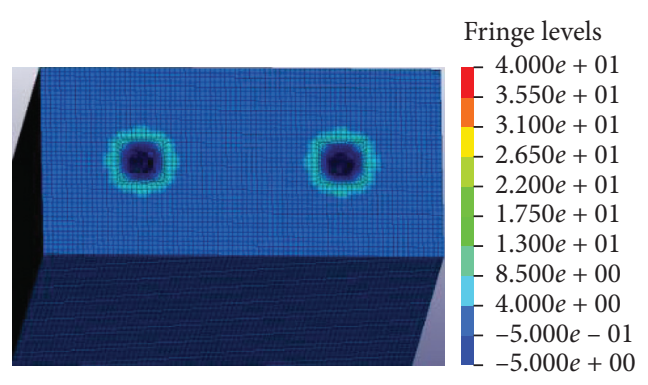

(a)

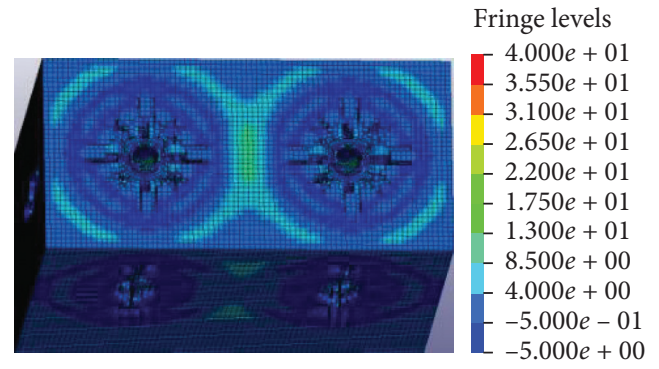

(c)

Fringe levels

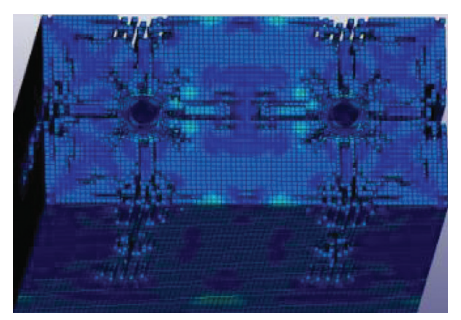

(e)

$4.000 e+01$
$-3.550 e+01$

$-3.100 e+01$

$-2.650 e+01$

$2.200 e+01$

$1.750 e+01$

$-1.300 e+01$

$8.500 e+00$

$-4.000 e+00$

$-5.000 e-01$

$-5.000 e+00$

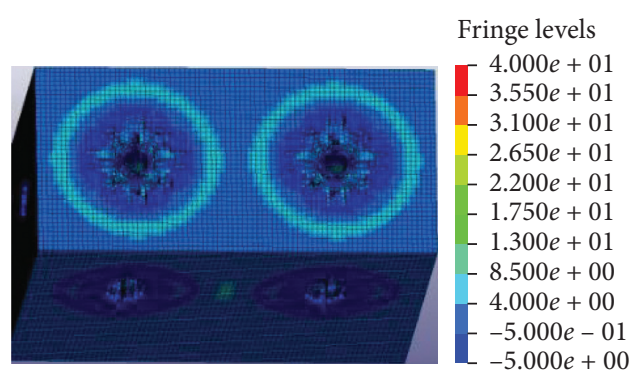

(b)

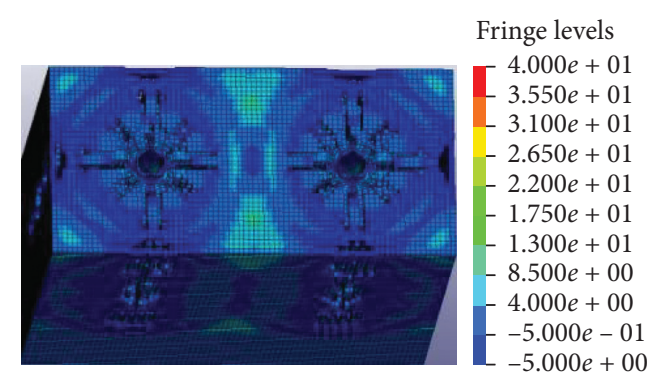

(d)

Fringe levels

$4.000 e+01$
$-3.550 e+01$

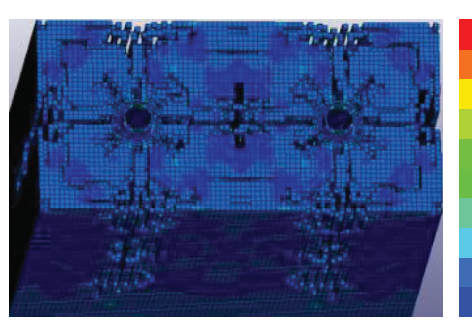

$-3.100 e+01$

$-2.650 e+01$

$-2.200 e+01$

$-1.750 e+01$

$-1.300 e+01$

$8.500 e+00$

$-4.000 e+00$

$-5.000 e-01$

(f)

Figure 8: The whole process of a loading concrete beam segment with single-row holes. (a) $t=55 \mu \mathrm{s}$. (b) $t=75 \mu \mathrm{s}$. (c) $t=85 \mu \mathrm{s}$. (d) $t=95 \mu \mathrm{s}$. (e) $t=120 \mu \mathrm{s}$. (f) $t=160 \mu \mathrm{s}$.

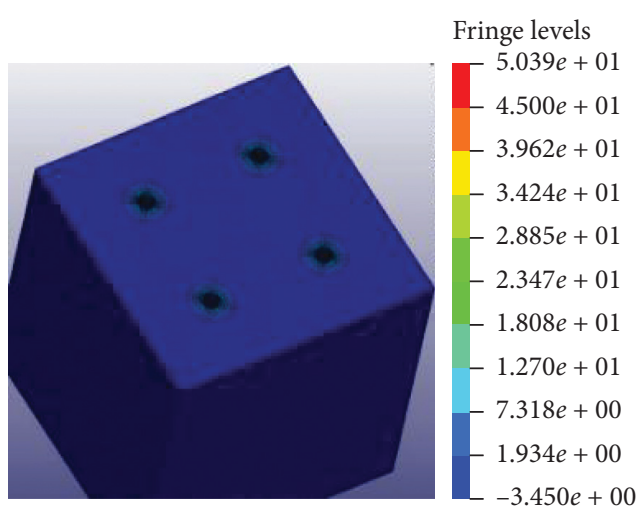

(a)

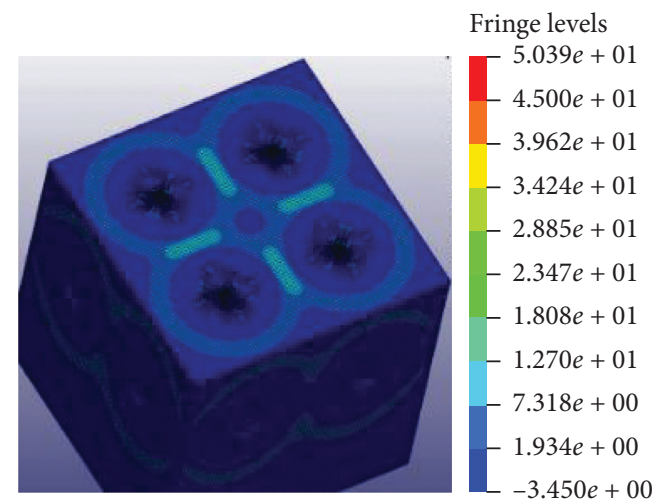

(b)

Figure 9: Continued. 


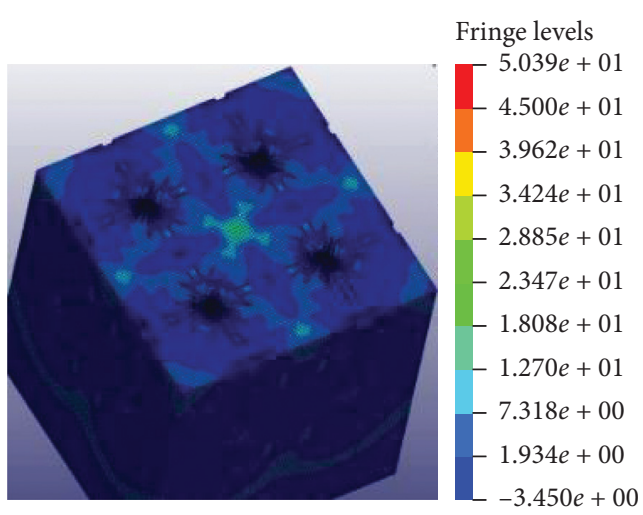

(c)

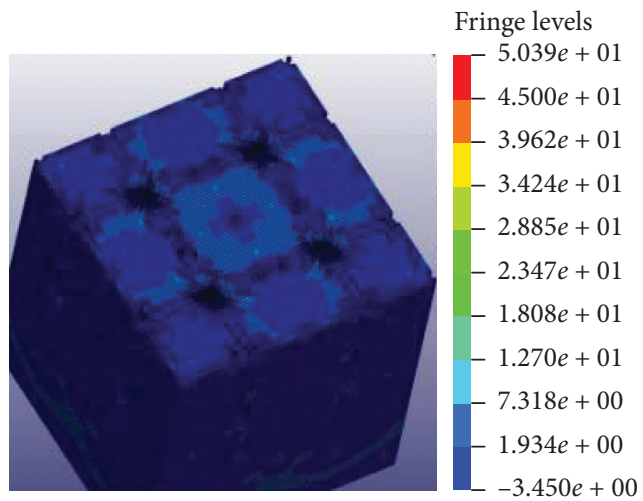

(e)

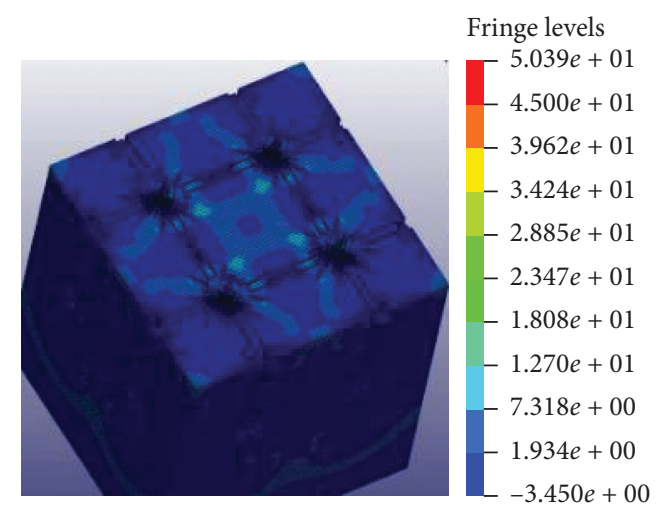

(d)

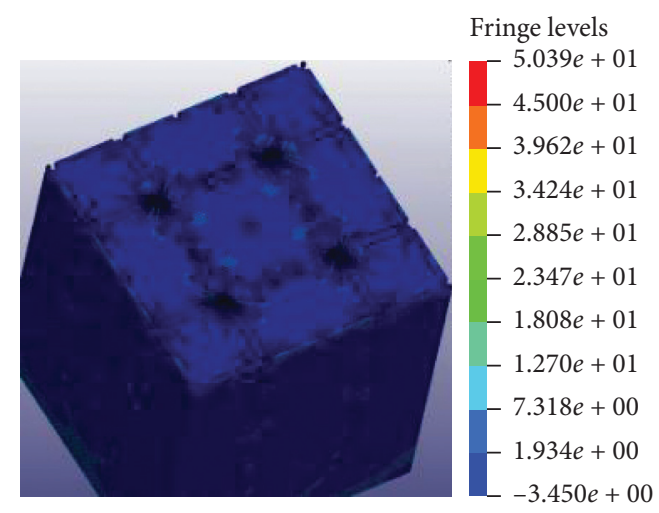

(f)

Figure 9: The whole process of a loading concrete beam segment with double-row holes. (a) $t=55 \mu \mathrm{s}$. (b) $t=75 \mu \mathrm{s}$. (c) $t=85 \mu \mathrm{s}$. (d) $t=95 \mu \mathrm{s}$. (e) $t=120 \mu \mathrm{s}$. (f) $t=160 \mu \mathrm{s}$.

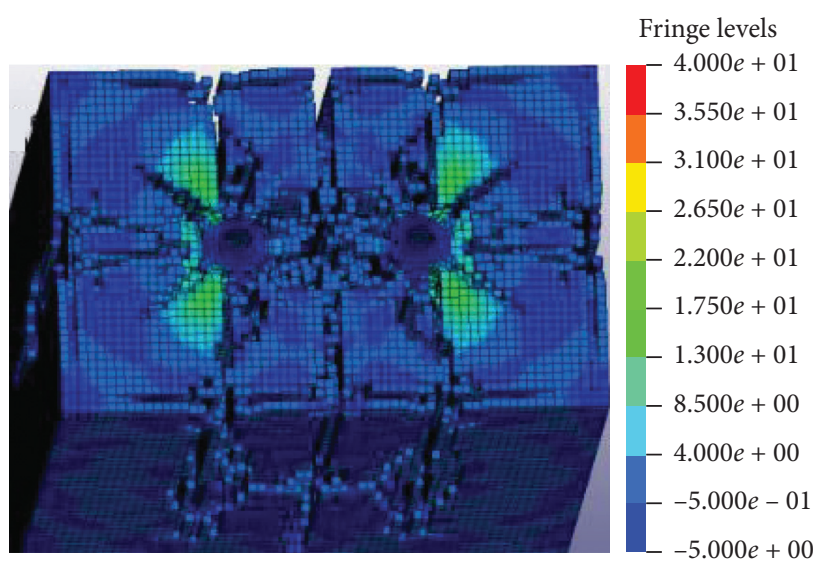

(a)

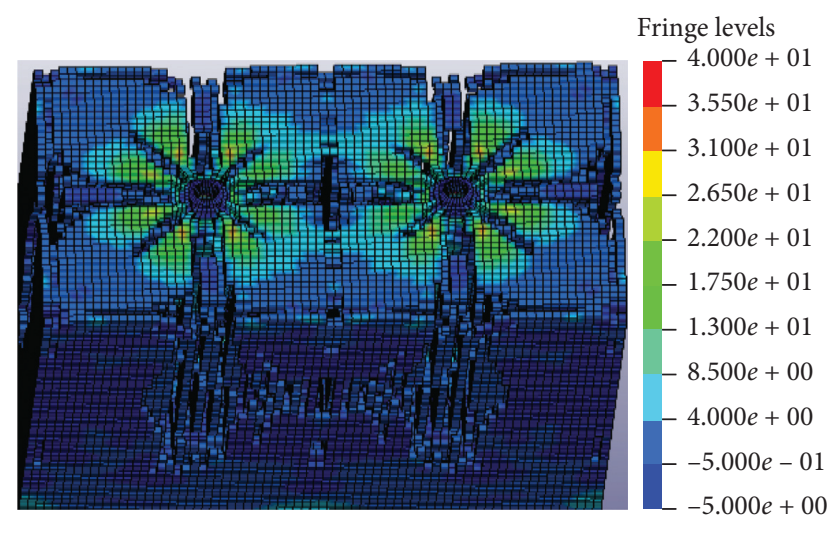

(b)

Figure 10: Continued. 


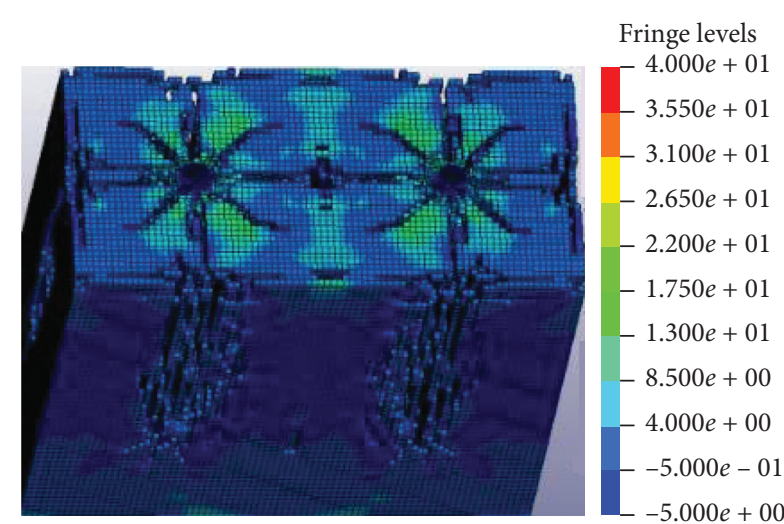

(c)

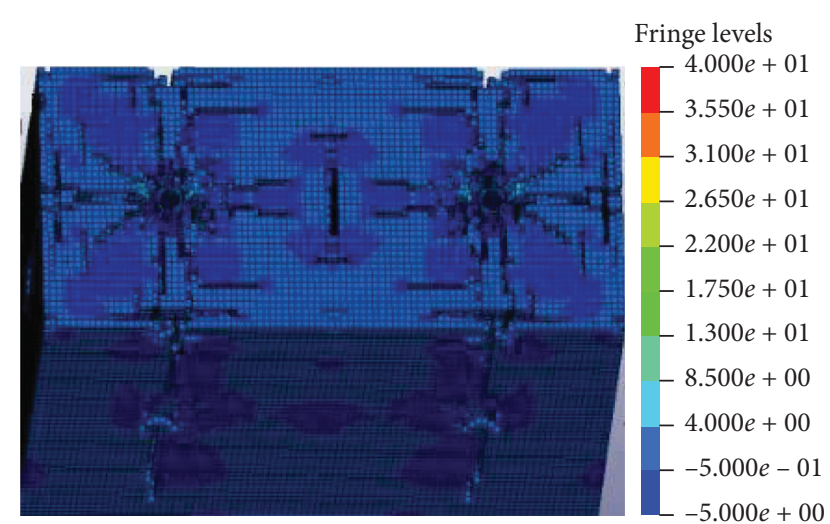

(d)

FIGURE 10: Simulation results of beams with different hole spacing when the aperture is $30 \mathrm{~mm}$. (a) $S=200 \mathrm{~mm}$. (b) $S=300 \mathrm{~mm}$. (c) $S=400 \mathrm{~mm}$. (d) $S=500 \mathrm{~mm}$.

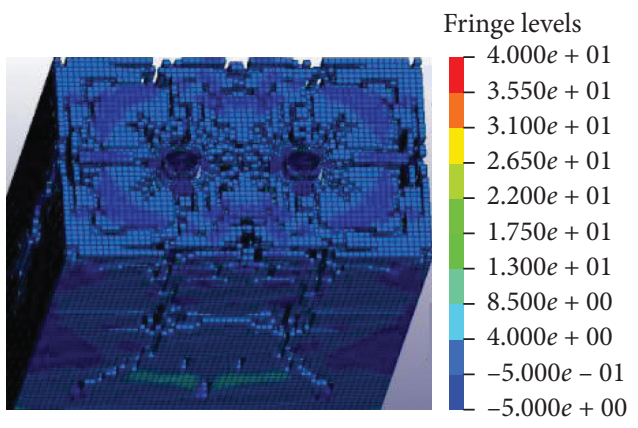

(a)

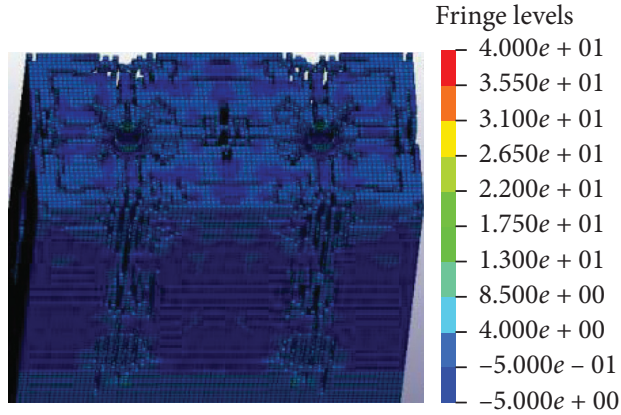

(c)

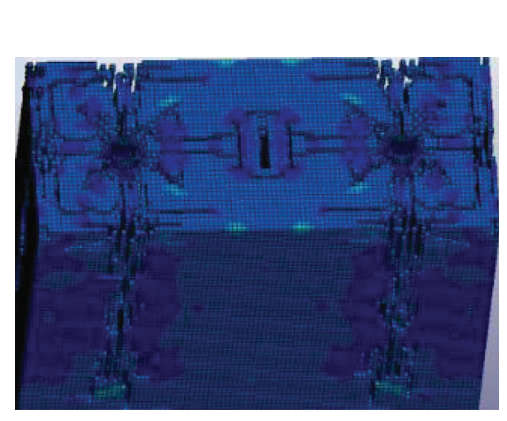

Fringe levels

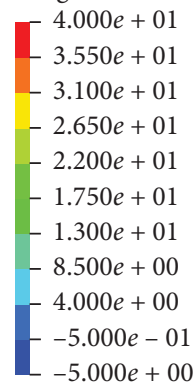

(e)

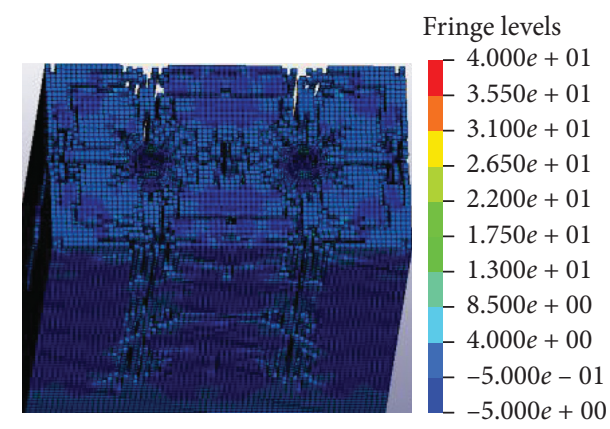

(b)

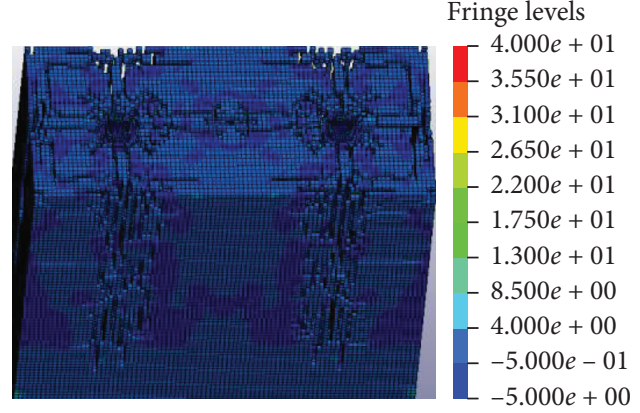

(d)

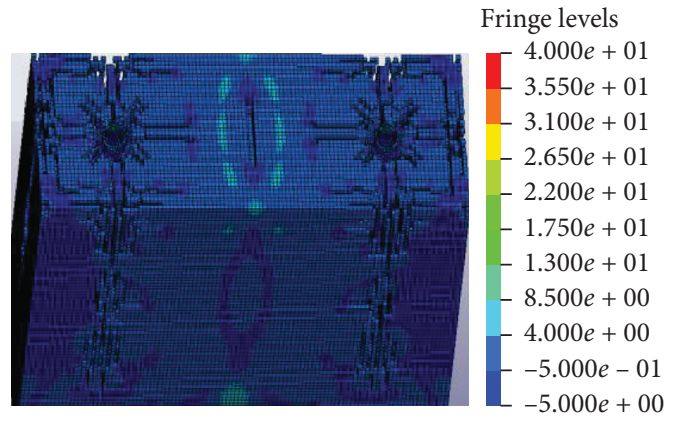

(f)

FIGURE 11: Simulation results of beams with different hole spacing when the aperture is $50 \mathrm{~mm}$. (a) $S=200 \mathrm{~mm}$. (b) $S=300 \mathrm{~mm}$. (c) $S=400 \mathrm{~mm}$. (d) $S=500 \mathrm{~mm}$. (e) $S=600 \mathrm{~mm}$. (f) $S=700 \mathrm{~mm}$. 


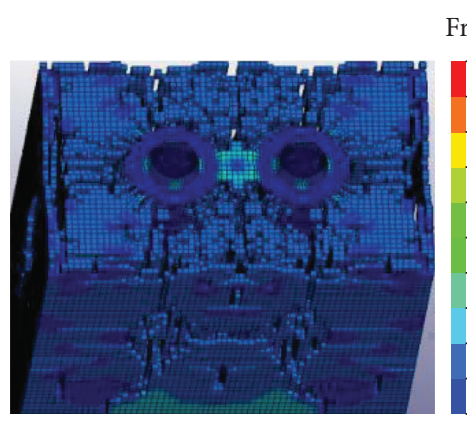

Fringe levels

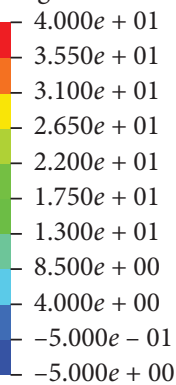

(a)

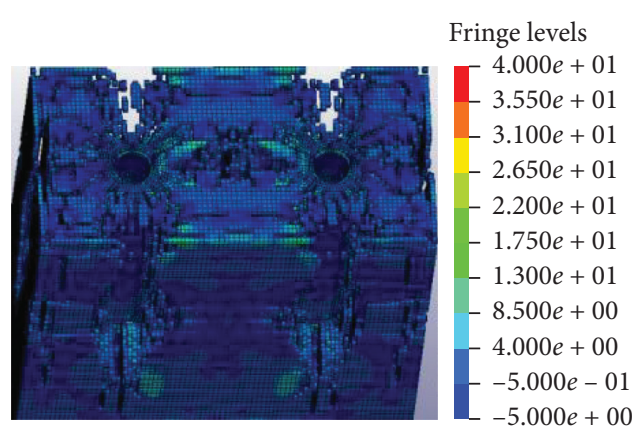

(c)

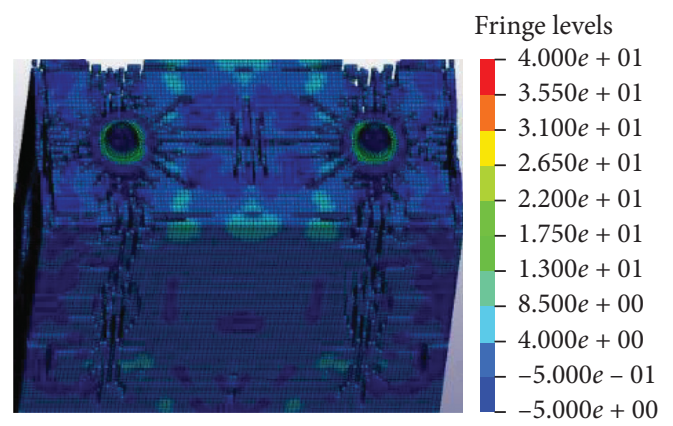

(e)

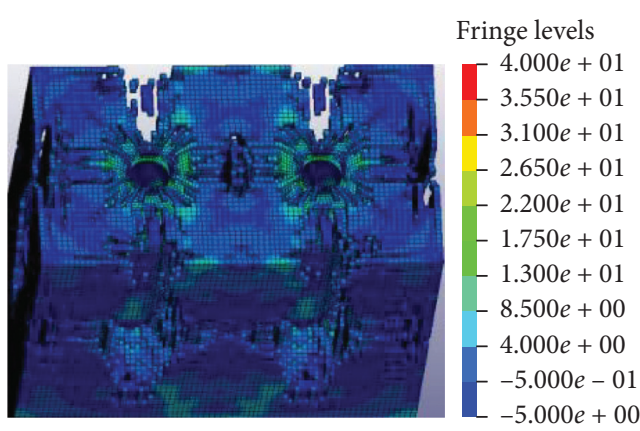

(b)

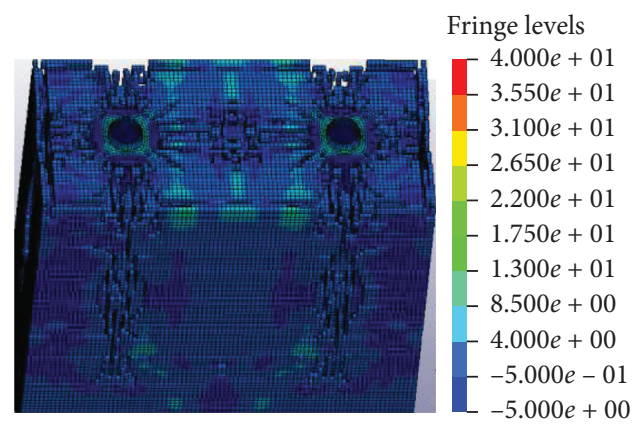

(d)

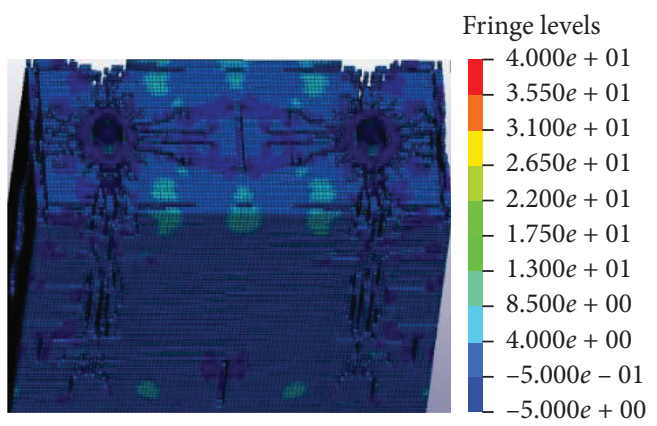

(f)

FIGURE 12: Simulation results of beams with different hole spacing when the aperture is $70 \mathrm{~mm}$. (a) $S=200 \mathrm{~mm}$. (b) $S=300 \mathrm{~mm}$. (c) $S=400 \mathrm{~mm}$. (d) $S=500 \mathrm{~mm}$. (e) $S=600 \mathrm{~mm}$. (f) $S=700 \mathrm{~mm}$.

(1) Analysis of Simulation Results When the Aperture Is $30 \mathrm{~mm}$. The crack development of concrete beam segments with hole spacing $S=200 \mathrm{~mm}, 300 \mathrm{~mm}, 400 \mathrm{~mm}$, and $500 \mathrm{~mm}$ was calculated, respectively. The influence of hole spacing on the fracture effect of concrete beam sections was investigated. The aperture is $30 \mathrm{~mm}$, and the end (edge) spacing is $250 \mathrm{~mm}$. The calculation results are shown in Figure 10.

It can be seen from Figure 10 that with the decrease of hole spacing, the crushing effect of concrete beam segment becomes more and more obvious. When the hole spacing was $200 \mathrm{~mm}$ and $300 \mathrm{~mm}$, as shown in Figures 10(a) and 10 (b), there were many and connected cracks between adjacent holes, and the transverse cracks starting from the holes also extended to the outer edge of the concrete beam sections. When the hole spacing was $400 \mathrm{~mm}$, as shown in Figure 10(c), a connected main crack was formed between the two holes, and the transverse cracks starting from the holes also extended to the outer edge of the concrete beam segments. When the hole spacing was $500 \mathrm{~mm}$, as shown in Figure 10(d), two main longitudinal cracks were formed between two adjacent holes but not connected, while two transverse cracks were formed along the concrete beam segment starting from the holes and extending to the outer edge of the concrete beam. According to the analysis mentioned above, when the hole spacing was $400 \mathrm{~mm}$ or less and the aperture was $30 \mathrm{~mm}$, the fractures between adjacent holes were connected. When the hole end (edge) spacing was $250 \mathrm{~mm}$, the transverse cracks starting from the holes were connected with the outer edge of the concrete beam segment to achieve crushing effect. Considering the construction efficiency and economic factors, the hole spacing of $400 \mathrm{~mm}$ is the optimal scheme.

(2) Analysis of Simulation Results When the Aperture Is $50 \mathrm{~mm}$. The crack development of concrete beam segments 


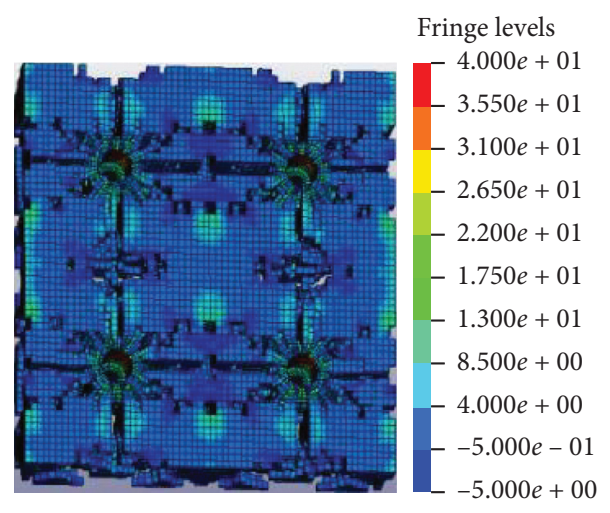

(a)

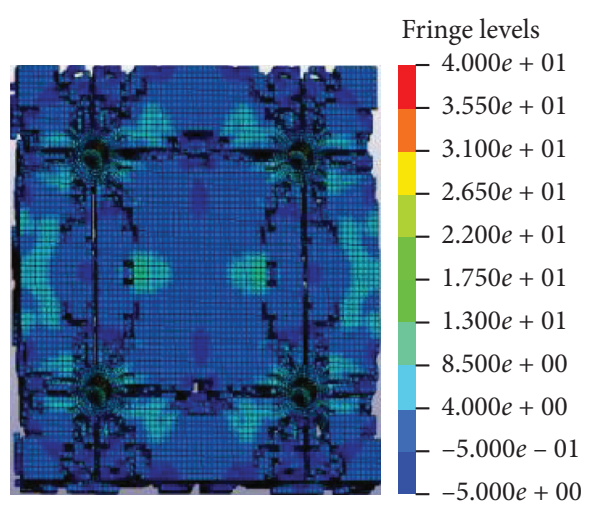

(b)

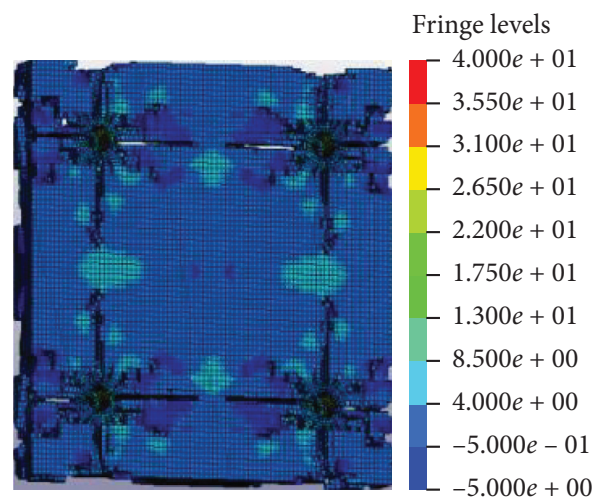

(c)

FIgURE 13: Simulation results of concrete slabs with different hole spacing. (a) $S=200 \mathrm{~mm}$. (b) $S=300 \mathrm{~mm}$. (c) $S=400 \mathrm{~mm}$.

with hole spacing $S=200 \mathrm{~mm}, 300 \mathrm{~mm}, 400 \mathrm{~mm}, 500 \mathrm{~mm}$, $600 \mathrm{~mm}$, and $700 \mathrm{~mm}$ was calculated, respectively. The influence of hole spacing on the fracture effect of concrete beams was investigated. The aperture is $50 \mathrm{~mm}$, and the end (edge) spacing is $250 \mathrm{~mm}$. The calculation results are shown in Figure 11.

It can be seen from Figure 11 that with the decrease of hole spacing, the crushing effect of concrete beam segment becomes more and more obvious. When the hole spacing was $200 \mathrm{~mm}$, there were many fractures and connections between adjacent holes, as shown in Figure 11(a). When the hole spacing was $300 \mathrm{~mm}$, as shown in Figure 11(b), the cracks between adjacent holes were connected and extended to the outer edge of the concrete beam segment. When the hole spacing was $400 \mathrm{~mm}$, as shown in Figure 11(c), two main transverse and longitudinal cracks were formed centered on the holes, which extended to the edge of the concrete beam and were connected. When the hole spacing was $500 \mathrm{~mm}$, as shown in Figure 11(d), the transverse fractures starting from the holes were not fully connected. When the hole spacing was greater than $500 \mathrm{~mm}$, the transverse cracks between adjacent holes were not connected, as shown in Figures 11(e) and 11(f). So, the hole spacing of $400 \mathrm{~mm}$ is the optimal scheme.

(3) Analysis of Simulation Results When the Aperture Is $70 \mathrm{~mm}$. The crack development of concrete beam segments with hole spacing $S=200 \mathrm{~mm}, 300 \mathrm{~mm}, 400 \mathrm{~mm}, 500 \mathrm{~mm}$, $600 \mathrm{~mm}$, and $700 \mathrm{~mm}$ was calculated, respectively. The influence of hole spacing on the fracture effect of concrete beam sections was investigated. The aperture is $70 \mathrm{~mm}$, and the end (edge) spacing is $250 \mathrm{~mm}$. The calculation results are shown in Figure 12.

It can be seen from Figure 12 that with the decrease of hole spacing, the crushing effect of concrete beam segment becomes more and more obvious. When the hole spacing was $200 \mathrm{~mm}$, as shown in Figure 12(a), numerous subtle fractures were generated around the holes, but no fractures were generated in the compression zone formed between the holes. When the hole spacing was $300 \mathrm{~mm}$, as shown in Figure 12(b), the transverse cracks starting from the holes extended to the outer edge of the concrete beam segment and were connected. When the hole spacing was $400 \mathrm{~mm}$, as shown in Figure 12(c), the transverse cracks starting from the holes connected and extended to the edge of the concrete beam. When the hole spacing was $500 \mathrm{~mm}$, as shown in Figure $12(\mathrm{~d})$, the transverse cracks starting from the bore extended to the edge of the concrete beam segment, but the cracks on the connection between the two bore holes were not fully connected. When the hole spacing was greater than $500 \mathrm{~mm}$, the transverse cracks between the two adjacent holes were not connected, as shown in Figures 12(e) and $12(\mathrm{f})$. So, the hole spacing of $400 \mathrm{~mm}$ is the preferred scheme. 


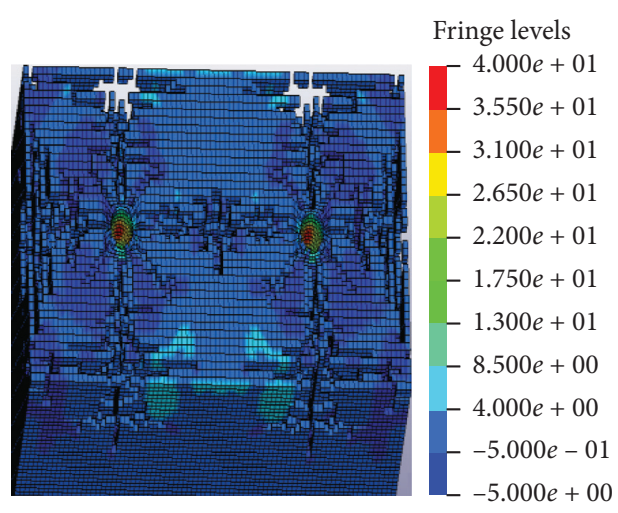

(a)

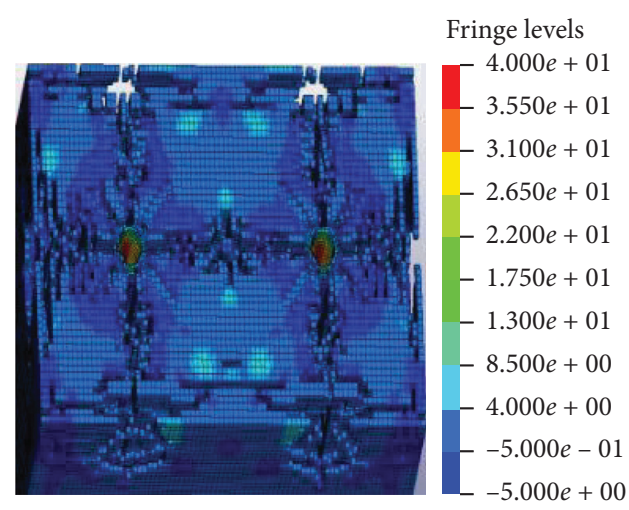

(b)

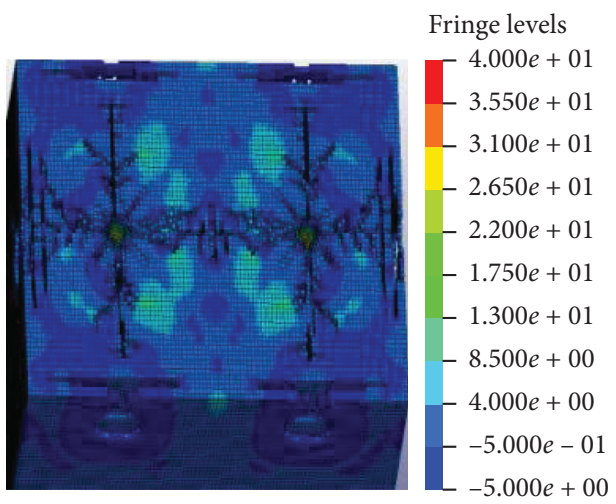

(c)

Figure 14: Simulation results of the concrete columns with different edge spacing. (a) $b=400 \mathrm{~mm}$. (b) $b=500 \mathrm{~mm}$. (c) $b=600 \mathrm{~mm}$.

Based on the analysis mentioned above, it can be seen that with the increase of hole diameter and the decrease of hole spacing, the crushing effect of concrete beam segment is enhanced. When the hole spacing is less than $400 \mathrm{~mm}$, the concrete beams under each aperture can be effectively broken. Considering the common aperture in construction, reasonable crushing size of concrete, and working efficiency, it is suggested to take the aperture of $50 \mathrm{~mm}$ and hole distance of $400 \mathrm{~mm}$ as the optimal crushing scheme.

5.2.4. Analysis of Simulation Results of Concrete Slabs. For concrete slab segments, the end (edge) spacing is $250 \mathrm{~mm}$, the thickness is $140 \mathrm{~mm}$, and the aperture depth is $120 \mathrm{~mm}$. Under the hole spacing of $300 \mathrm{~mm}, 400 \mathrm{~mm}$, and $500 \mathrm{~mm}$, the crushing effects of slabs with $50 \mathrm{~mm}$ aperture are shown in Figure 13.

As can be seen from Figure 13(a), when the hole spacing $S=300 \mathrm{~mm}$, the cracks between adjacent holes were connected and generated oblique cracks, and the cracks extended to the outer edge of the concrete slab segment, and the crushing effect is good. As shown in Figure 13(b), when hole spacing $S=400 \mathrm{~mm}$, cracks between adjacent holes were connected and extended to the outer edge of concrete slab segment. As shown in Figure 13(c), when the hole spacing $S=500 \mathrm{~mm}$, the cracks between adjacent holes were not connected, and the cracks starting from the holes extended to the outer edge of the slab. In conclusion, the crushing effect and economic benefit are the best when the hole spacing $S=400 \mathrm{~mm}$.

\subsubsection{Analysis of Simulation Results of Concrete Columns.} The concrete columns can be drilled longitudinally on one side, which are similar to that of concrete beams. However, the column width is generally large, and a single row of holes may lead to cracks that cannot reach the edge of the column. The concrete columns were established with three types of section size: $b \times h=400 \mathrm{~mm} \times 400 \mathrm{~mm}, 500 \mathrm{~mm} \times 500 \mathrm{~mm}$, and $600 \mathrm{~mm} \times 600 \mathrm{~mm}$. The edge spacing of the holes in the column with section size of $400 \mathrm{~mm} \times 400 \mathrm{~mm}$ is $200 \mathrm{~mm}$, in the column with section size of $500 \mathrm{~mm} \times 500 \mathrm{~mm}$ is $250 \mathrm{~mm}$, and in the column with section size of $600 \mathrm{~mm} \times 600 \mathrm{~mm}$ is $300 \mathrm{~mm}$. The hole spacing of each type of column is $400 \mathrm{~mm}$ and the aperture is $50 \mathrm{~mm}$. The calculated results are shown in Figure 14.

As can be seen from Figure 14, when the hole spacing was $400 \mathrm{~mm}$, fractures between the two holes connected. It can be seen from Figures 14(a) and 14(b) that when the edge spacing of the hole was less than $250 \mathrm{~mm}$, the cracks starting from the hole centers extended to the side surface of the column for effective segmentation. Figure 14(c) shows that when the edge spacing of the hole was $300 \mathrm{~mm}$, the cracks starting from the hole centers did not extend to the side 
surface of the column, so the concrete column could not be effectively divided. It is suggested that when the section size of the concrete column is $500 \mathrm{~mm}$ or less, a single row of holes can be selected; otherwise, multiple rows of holes should be chosen. The layout principle of the holes is that the row distance is not more than $400 \mathrm{~mm}$, and the edge spacing is not more than $250 \mathrm{~mm}$.

\section{Conclusions}

(1) According to the results of the finite element analysis, with the increase of the hole diameter and the decrease of the hole spacing, the crushing effect of concrete members is improved.

(2) Under the different conditions of the diameter of $30 \mathrm{~mm}, 50 \mathrm{~mm}$, and $70 \mathrm{~mm}$, when the hole spacing is not more than $400 \mathrm{~mm}$, the cracks between the holes of the concrete beam are connected, and when the distance between the drilling end (side) of the concrete beam is $250 \mathrm{~mm}$, the cracks from the drilling can extend to the end (side) of the beam to achieve a crushing effect. Considering the common aperture and construction efficiency in actual construction, it is suggested to take the aperture of $50 \mathrm{~mm}$, hole distance of $400 \mathrm{~mm}$, and hole end (side) distance of $250 \mathrm{~mm}$ as the crushing scheme of concrete beam.

(3) The hole spacing of concrete slab and column should not be more than $400 \mathrm{~mm}$, and the layout scheme of multiple rows of holes can be used for the column with large section size and slab. The principle of hole spacing is not more than $400 \mathrm{~mm}$, and the hole margin spacing is not more than $250 \mathrm{~mm}$.

\section{Data Availability}

The data used to support the study are available at the website, https://pan.baidu.com/s/1NpdTBZB-UGrSilFCGtF jvg (extract the code: $2 c c y$ ).

\section{Conflicts of Interest}

The authors declare that they have no conflicts of interest.

\section{Acknowledgments}

This work was supported by the National Key R\&D Program of China (Grant no. 2017YFC0806100).

\section{References}

[1] W. Zuo, X. Li, F. Shi et al., "Effect of high voltage pulse treatment on the surface chemistry and floatability of chalcopyrite and pyrite," Minerals Engineering, vol. 147, pp. 106-170, 2020.

[2] D. Yan, D. C. Bian, F. Ren et al., "Study on breakdown delay characteristics based on high-voltage pulse discharge in water with hydrostatic pressure," Journal of Power Technologies, vol. 97, no. 2, pp. 89-102, 2017.
[3] G. Yan, Z. Zhang, B. Zhang et al., "Preferential sequence crushing of copper ore based upon high-voltage pulse technology," Minerals Engineering, vol. 131, pp. 398-406, 2019.

[4] X. Wang, N. Li, J. Du, and W. Wang, "Concrete crushing based on the high-voltage pulse discharge technology," Journal of Building Engineering, vol. 41, p. 102366, 2021.

[5] A. S. Yudin, N. V. Voitenko, and N. S. Kuznetsova, "Twosection pulse current generator for concrete and rocks destruction by splitting off," IEEE Transactions on Plasma Science, vol. 45, no. 1, pp. 3042-3045, 2017.

[6] X. Wang and J. Zhu, "Research and applications of highvoltage pulse discharge crushing," European Journal of Electrical Engineering, vol. 21, no. 2, pp. 157-163, 2019.

[7] Q. Zhang, "Study on the influencing factors of green building development from the perspective of city," M. S. thesis, Chongqing University, Chongqing, China, 2017.

[8] H. X. Jia, J. Q. Lin, and J. L. Liu, "Summary of seismic vulnerability analysis of building structures," Earthquake Disaster Prevention Technology, vol. 14, no. 1, pp. 42-51, 2019.

[9] V. Bazanov, "Application of environmentally friendly concrete demolition techniques in the repair of shipping locks// E3S Web of Conferences," EDP Sciences, vol. 91, Article ID 07020, 2019.

[10] M. C. Rao, S. K. Bhattacharyya, and S. V. Barai, Systematic Approach of Characterisation and Behaviour of Recycled Aggregate Concrete, pp. 39-63, Springer, Singapore, 2019.

[11] L. A. L. Ruiz, X. R. Ramón, and S. G. Domingo, "The circular economy in the construction and demolition waste sector-a review and an integrative model approach," Journal of Cleaner Production, vol. 248, no. 1, pp. 119-238, 2019.

[12] K. Uenishi, H. Yamachi, K. Yamagami, and R. Sakamoto, "Dynamic fragmentation of concrete using electric discharge impulses," Construction and Building Materials, vol. 67, pp. 170-179, 2014.

[13] U. Koji, S. Naoyuki, S. Shintaro et al., "Controlled disintegration of reinforced concrete blocks based on wave and fracture dynamics," Procedia Structural Integrity, vol. 2, pp. 350-357, 2016.

[14] A. S. Yudin, "Destruction of reinforced concrete by electric impulse discharges: experiment and simulation," in Proceedings of the the 18th International Conference on Positron Annihilation, Florida, FL, USA, December 2017.

[15] H. Yan, J. Zhang, N. Zhou et al., "The enhancement of lump coal percentage by high-pressure pulsed hydraulic fracturing for sustainable development of coal mines," Sustainability, vol. 11, no. 10, pp. 1-14, 2019.

[16] Y. Fazhi, "Using high-voltage electrical pulses to crush coal in an air environment: an experimental study," Powder Technology, vol. 298, pp. 50-56, 2016.

[17] S. H. Cho, S. S. Cheong, M. Yokota, and K. Kaneko, "The dynamic fracture process in rocks under high-voltage pulse fragmentation," Rock Mechanics and Rock Engineering, vol. 49, no. 10, pp. 3841-3853, 2016.

[18] N. Voitenko and A. S. Yudin, "Mobile electric-discharge blasting unit for splitting off and destruction of rocks and concrete," Key Engineering Materials, vol. 685, pp. 705-709, 2016.

[19] F. Yan, B. Lin, C. Zhu et al., "Experimental investigation on anthracite coal fragmentation by high-voltage electrical pulses in the air condition: effect of breakdown voltage," Fuel, vol. 183, pp. 583-592, 2016.

[20] H. C. Ulric and E. Panteki, "Modeling of concrete spallation with damaged viscoelasticity and retarded damage," 
International Journal of Solids and Structures, vol. 90, pp. 153-166, 2016.

[21] H. A. Illias, M. A. Tunio, H. Mokhlis, G. Chen, and A. H. A. Bakar, "Experiment and modeling of void discharges within dielectric insulation material under impulse voltage," IEEE Transactions on Dielectrics and Electrical Insulation, vol. 22, no. 4, pp. 2252-2260, 2015.

[22] W. Zuo, F. Shi, and E. Manlapig, "Modelling of high voltage pulse breakage of ores," Minerals Engineering, vol. 83, pp. 168-174, 2015.

[23] J. B. Liu, P. F. Han, and W. K. Zheng, "Numerical investigation of shield building for nuclear power plant subjected to commercial aircraft impact," Explosion and Shock Waves, vol. 36, no. 3, pp. 391-399, 2016.

[24] B. Huang, P. Li, J. Ma, and S. Chen, "Experimental investigation on the basic law of hydraulic fracturing after water pressure control blasting," Rock Mechanics and Rock Engineering, vol. 47, no. 4, pp. 1321-1334, 2014.

[25] G. Touya, T. Reess, L. Pécastaing, A. Gibert, and P. Domens, "Development of subsonic electrical discharges in water and measurements of the associated pressure waves," Journal of Physics D: Applied Physics, vol. 39, no. 24, pp. 5236-5244, 2006.

[26] K. Bao, The study on mechanism and experiment of hydraulic fracturing coal in high voltage electric pulse, Ph.D. thesis, Taiyuan University of Technology, Taiyuan, China, 2018. 